Journal of Teacher Education for Sustainability, vol. 11, no. 2, pp. 77-86, 2009

\title{
PEDAGOGICAL SYSTEMS THEORY AND MODEL FOR SUSTAINABLE HUMAN DEVELOPMENT IN EARLY CHILDHOOD EDUCATION AND CARE (ECEC)
}

\author{
Ulla Härkönen \\ University of Joensuu, Finland
}

\begin{abstract}
The contexts are kindergarten teacher student education, early childhood education and the author's long term research process of constructing a new pedagogical systems theory. The two systems models, which the author created earlier, function now in a theoretical background. The models are different but both of them reflect on early childhood education and care (ECEC). The exact focused question is, what the interconnections of the two different models of ECEC are. Solutions will be shown by making a cross tabulation between these two qualitative models. The results will construct forward the new pedagogical systems theory of ECEC. This theory and a corresponding model can help teachers to become responsible mentors for sustainable development, especially for children's education for sustainable human development and well-being.
\end{abstract} Key words: early childhood education and care (ECEC); pedagogical systems theory; pedagogical systems model; sustainable human development.

\section{Introduction}

The main long-term aim of the author has been to develop a new theory for early childhood education and care (ECEC). In this article, one detail of the mentioned theory will be resulted. The theoretical part consists of the explanations of the main concepts and the two models on early childhood education (ECE). After that the main problem, a methodological view, methods, results and discussion of the study are presented.

\section{Theoretical background}

\section{About the main concepts}

In European context the generally used concept is early childhood education and care (ECEC). "'Education' and 'care' are combined in the phrase to underline, that services for young children can combine care, developmental and learning opportunities" (European Commission, 2009, p. 7). 
In the Finnish context, the accepted concept is varhaiskasvatus (literally translated early education, meaning is the same as early childhood education). This concept implies education under school age which means under seven years of age. In Finland, the concept preschool means only six year olds. In the Finnish context, it is not usual to add care (hoito) after early childhood education (varhaiskasvatus) - besides when the text is meant for European and international readers. It is thought that care belongs under and inside early childhood education (varhaiskasvatus). In the results of the author's studies (Härkönen, 2003a, 2008, 2009), many other concepts are at the same position as care, when speaking about their relations to the concept early childhood education. They are education, teaching, learning and development, even socialization, civilization and spiritualization, which are found in literature.

What does it mean when we speak about sustainable early childhood education? Jämsä (2006) has analyzed this thing very exactly. He tells that sustain means supporting and maintaining something, to hold up, giving a firm groundwork for something to hold it up permanently. In the concept sustainable, -able indicates that the function of stem is capable of being executed, executable. Jämsä (2006) continues that educe means bringing out, eliciting, developing or evolving, especially from a latent or potential state. Educe also means calling forth or bringing out (something latent, hidden, or unexpressed. Jämsä (2006, p. 14) says that "sustainable education is a new research subject".

The purposes of sustainable education can be promoting equity, improving our quality of life and well-being, sustaining our natural resources and protecting health. Jämsä (2006, p. 28) "underlines that sustainable education ... is not separable from the general principles of education and ... it is an essential part of ethical education". His conviction is "that personal ethical choices, the embodiment of the individual and social good, give a transcendent ground for ethical views in all education and sustainable education... Sustainable education tries to awaken people to a deep personal awareness of the different consequences of different moral choices".

About sustainability Jämsä $(2006$, p. 28) says that it is "usually confined to the survival of nature and the human action for or against it", and that "sustainable education stresses the human responsibility for the consequences of our misuse of natural sources". This is not enough in his views. "The risk from inside our species should be in the focus of our attention, as well." "Sustainable education necessarily needs a general view of moral education as well."

The new pedagogical systems theory is based on historical educational ideas. Cohen and Manion (1994, p. 46) writes, that "the historical study of an educational idea or institution can do much to help us understand how our present educational system has come about; and this kind of understanding can in turn help to establish a sound basis for further progress. Historical research in education can also show how and why educational theories and practices developed. It enables educationalists to use former practices to evaluate newer, emerging ones".

The new pedagogical systems theory is going to consist of pedagogical views. It will deal with philosophical, educational and pedagogical values, aims, goals, subjects, methods. It will show links to different sciences and knowledge areas and it will also show how different curriculums and programs can well be planned and evaluated (Figure 1 ). These kinds of phenomena have been and are pedagogical by their nature (Gudjons, 2003; Helenius \& Korhonen, 2008). 
The systems theory means (Heylighen \& Joslyn, 1992, pp. 1-2) "the transdisciplinary study of the abstract organization of phenomena, independent of their substance, type, or spatial or temporal scale of existence. It investigates both the principles common to all complex entities ... and the models which can be used to describe them." "Rather than reducing an entity ... to the properties of its parts or elements ... systems theory focuses on the arrangement of and relations between the parts which connect them into a whole (cf. holism)."

"A system is a dynamic and complex whole, interacting as a structured functional unit. Energy, material and information flow between the different elements that compose the system." "A holistic system is any set (group) in interdependent or temporally interacting parts. Parts are systems themselves and are composed of other parts, just as systems are generally parts or holons of other systems” (Wikipedia, 2009).

"Systems thinking is a powerful set of problem solving tools and techniques based on system analysis and design, that helps us avoid unintended consequences and find optimal solutions to complex problems." It is "a philosophy that looks at the world in terms of just what it says - systems. The entire world can be seen as one big system which encompasses countless smaller systems." "A systems thinking approach may help you break through and find more effective, more sustainable solutions" (Senge, 2009).

Rapoport (1968, pp. 452-453) says that the definition of systems should also consider the language, not only the physical systems. He writes (p. 453), that "social scientists speak of economic and political systems; philosophers, about systems of thought". "In the larger sense, a language system may also include the referential world and even the speakers." In accordance with Parsons (1968), the human action has its subsystems, among which one is a cultural system. It comprises the language, communication, beliefs and ideas. Chang-Gen (1990) divides real systems into categories like the natural systems, the social systems and the systems of thinking.

Thus, the concept of early childhood education is a system, too. It has many subsystems which have relationships with each other and with the whole entity.

The author has said that the pedagogical systems theory will be a new theory for early childhood education. New means just the characteristic features which systems thinking means. It is a quite different way of seeing than a common way of cause and effect thinking.

The above mentioned concepts like care, education, teaching, learning, development, socialization, civilization and spiritualization can be understood as goals and aims of education. At least in Finland, one concept of them is the thing, it is learning. But especially in approaches, originated from the developmental psychology, the development of children has seen as a central process in children's life course. Valsiner (2000) presents a cultural-historical theory of development, Bronfenbrenner (1989) has created the ecological systems theory of human development and in Vasta's (2002) book there are six theories about children's development. There are also many books where developmental theories are applied to the early childhood education and care (Bredekamp, 1987; Hakkarainen, 2002; Robinson, 2008; Wood, 2008). In each theory, the meaning is to give knowledge about a healthy human development process.

The concept sustainable human development has not been usually used in developmental theories. However, an application from the common concept sustainable development to sustainable human development has already been done. Sustainable human development is a new concept. Perhaps we must begin about sustainable education. 


\section{The general systems model of early childhood education thinking}

The general systems model of early childhood education and preschool thinking (GSM of ECE) is depicted in Figure 1 as a result of a creation process by the author (Härkönen, 2003b, 2006, 2008, 2009).

Figure 1 reflects pedagogical thinking of historical education pedagogues like Froebel, Steiner, Montessori, Neill and Dewey. In the article The new Systems Theory of Early Childhood Education and Preschool as a Frame of Reference for Sustainable Education (Härkönen, 2003b, pp. 5-6), the systems character of the pedagogues' educational thinking was found and described exactly. The lines between the main context areas link them together in systems way.

It is extremely important to notice that the question is about the model of thinking. The word views which lies in every context areas (white ovals) is always written in the plural form. This means that the context areas consist of diversities of opinions, beliefs, interpretations and also diversities of different kinds of theories.

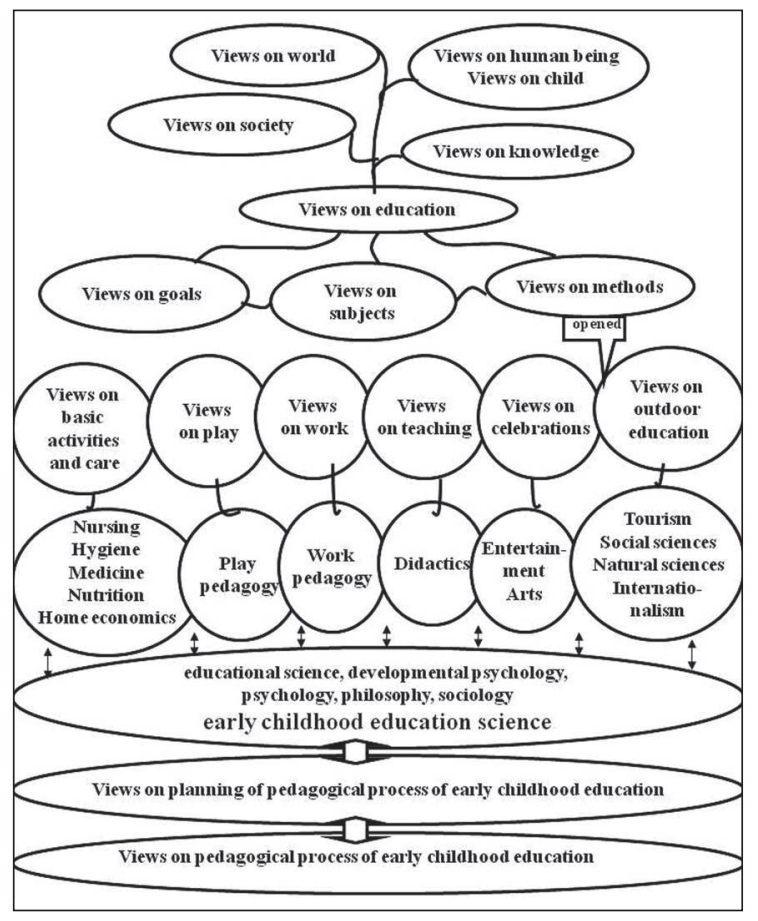

Figure 1. The general systems model of early childhood education and preschool thinking (GSM of ECE) (Härkönen Ulla 2008)

\section{The model of the concept of early childhood education}

The model entitled as The four extensions and eight intensions of the early childhood education concept as a systems model (Figure 2) is presented with brief comments. A text analysis and a concept analysis method were used in studying the Finnish early childhood education textbooks (Härkönen, 2003a, 2003b, 2006, 2008, 2009). 


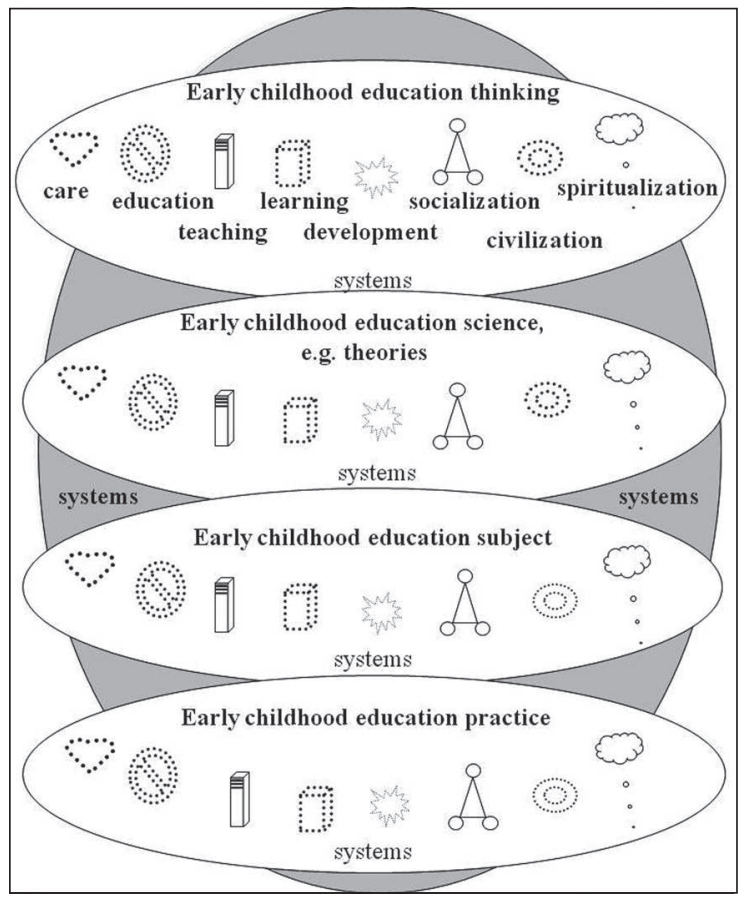

Figure 2. The four extensions and eight intensions of the early childhood education concept as a systems model (Härkönen Ulla 2008) (EECERA_08: spiritualization added)

The 'extension' means an application area of the concept. It must look at what phenomena in the world will suit the concept or fulfill the criteria given in the intension. The 'intension' or content means the criteria or a set of signs that is held valid for a given period of time (Karvonen, 2003).

Figure 2 shows that the concept of early childhood education comprises four extensions: thinking, science, subject and practice extensions. The intensions which make the mentioned extensions just as early childhood education are care, education, teaching, learning, development, socialization, civilization and spiritualization. Extensions are in systems relationships with each other, intensions are in systems relationships with each other. Extensions and intensions are in numerous relationships with each other.

\section{Problems}

After getting the mentioned models ready, the new question arose about the interconnections of them (Figure $1 \&$ Figure 2). This study will answer the following question:

What are the interconnections of the mentioned two models: The general systems model of early childhood education and preschool thinking (GSM of ECE) (Figure 1) and The four extensions and eight intensions of the early childhood education concept as a systems model (Figure 2)? 


\section{Methodology and methods}

Parsons (1968, p. 458) has said that "methodologically, one must distinguish a theoretical system which is a complex of assumptions, concepts and propositions having both logical integration and empirical reference, from an empirical system, which is a set of phenomena in the observable world that can be described and analyzed by means of a theoretical system". This means that that the theoretical systems model have also connections to the observable early childhood education.

In a content analysis the question is how to give a greater conceptual order to the specific data (Strauss, 1987, p. 143). Relational analysis, like conceptual analysis, begins with the act of identifying concepts present in a given text or set of texts. However, relational analysis seeks to go beyond presence by exploring the relationships between the concepts identified. Relational analysis has also been termed semantic analysis (Palmquist, Carley, \& Dale, 1997).

I this study three different models are presented. "On the one hand, a model can be a representation of a selected part of the world (the 'target system'). Depending on the nature of the target, such models are either models of phenomena or models of data. On the other hand, a model can represent a theory in the sense that it interprets the laws and axioms of that theory" (Frigg \& Hartman, 2006, p. 2.).

As a method, a cross tabulation between the two verbalized and modeled data, were made. Cross-tabulations are the powerful ways to combine qualitative coding with the more descriptive organization of data (Lewins \& Silver, 2007). Many research problems are quite complicated, and working out graphic means for helping to understand them requires innovative imagery and careful consideration (Strauss, 1987).

\section{Results}

Figure 1 bears the validity of historically sustained features of pedagogical thinking over three hundred years in Europe and in the rest of the world; Figure 2 was constituted on the basis of the definitions of the concept of early childhood education analyzed from Finnish text books on early childhood education and preschool which cover about a period of thirty to forty years just in one country. The model 1 has a stronger historical sustainable tenability and legitimacy.

In both cases, textual data was analyzed by a content analysis. Both resultant models are qualitative descriptive models. The analysis of the native literature may be more credible than the literature of different ages and in languages. However, the author has tested both models in several contexts and they both seem to be credible.

Now in this study these models were cross-tabulated. The results are seen in Figure 3 entitled Pedagogical systems theory and its core value contexts, presented as a systems model. The content of Figure 1 is marked with blue (or black and thick in colourless printing) rimmed oblong areas which consist of the parts and the whole of the General systems model of early childhood education and preschool thinking.

It must be noticed that Figure 1 reveals only about one extension; it must be early childhood science (because this area consists, for instance, of theories). The result is that Figure 1 shows new and versatile intensions for the extension of early childhood education science. 


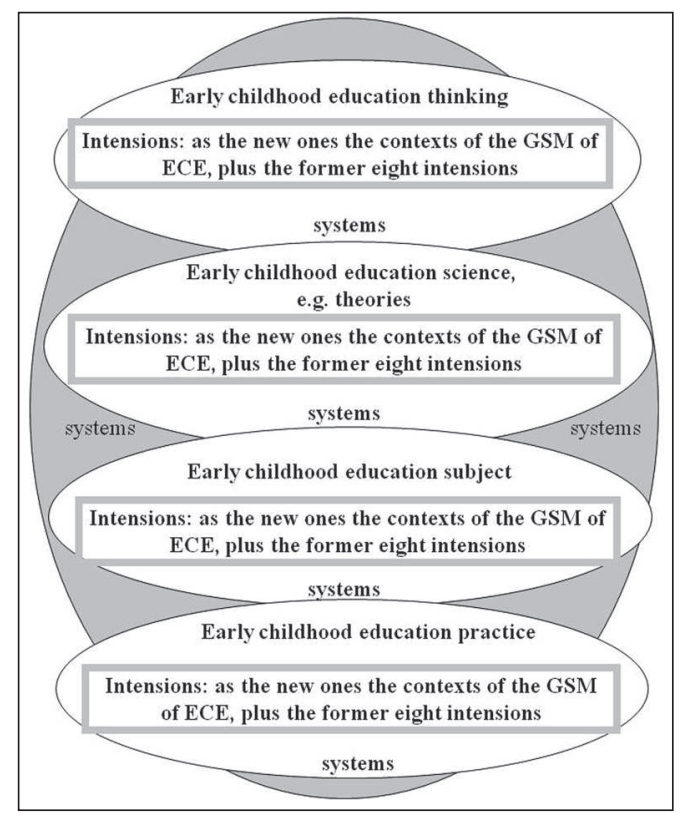

Figure 3. Pedagogical systems theory and its core value contexts, presented as a systems model (Härkönen Ulla 2008)

It is said (Church, 2001) that the intension of a concept consists of the qualities or properties which go to make up the concept. Logically the same content must be included in every extension because otherwise the question cannot be about the same concept (early childhood education). That is why Figure 1 must be put inside each extension of Figure 2.

Now the four extensions and new pedagogical intensions are found for the concept of early childhood education (Figure 3). But also the earlier eight intensions are still valid because they can be found in Figure 1: the concept of care have its own context area, education belongs to all contexts, teaching has its own context area, learning and development lies there in views on human being, concepts of socialization and civilization and spiritualization belong to the area on human being but these are united as the whole system.

However, it must be said that the new intensions (Figure 1) for the four extensions of the concept of early childhood education (ECE) are much more informative. They give a clear pedagogical content for the extensions of the concept of early childhood education (ECE). They have long-term sustainability. Instead of that the former intensions, which are depicted in Figure 2, have not so solid, harmonious and continuous sustainability in history, but all of them can be found in different combinations in literature, however.

We can notice that care is only an intension of the concept of early childhood education, not a separate concept. In the systems context of early childhood education, care gets an educational character and goals. That also means sustainability in caring activities because doing caring activities in this way suggests developmentally and educative appropriate action. 


\section{Discussion}

Due to the title of the study the next question arises: How do the new pedagogical systems theory and the corresponding model function for sustainable human development?

The most important characters of the pedagogical systems theory and the corresponding model are that they represent historical, pedagogical, systemic, holistic and comprehensive, diverse and pluralist, interpretative and semiotic, egalitarian, democratic and tolerant values. These kinds of values can construct sustainable education which takes account sustainability also in children's, teachers', parents' and all human beings' development (Schreiner, 2009). All this is important in an intercultural dialogue all over the world (Council of Europe, 2008).

The author thinks that the thoughts of Jämsä (2006) could well characterize sustainable education which could for one's part promote sustainable, good and healthy human development, also cultivate, civilize and spiritualize human beings from outside and inside.

Diverse ways - which are present in this theory and model - cannot, however, offer fully freedom to do everything whatsoever everybody wants. The risk is that it is wanted more and more about children's development, more than their optimal developmental limits allow. If the teachers and adults encumber children's development, they exploit the optimal possibilities for well-being. The principles of equity, restriction, limitation and control of teachers', parents' and society's activities are needed in education and in ambitions according to children's development.

The further research might concentrate on value contexts of the new layered systems model of early childhood education, the possible influences and meanings in relation to human development.

\section{References:}

Bredekamp, S. (Ed.). (1987). Developmentally appropriate practice in early childhood programs. Washington DC: NAEYC.

Bronfenbrenner, U. (1989). Ecological systems theory. Annals of Child Development, 6, 187-249.

Chang-Gen, B. (1990). Major systems theories throughout the world. Behavioral Science, 35(2), 79-103.

Church, A. (2001, May 16). SOU: Intension \& extension. In D. Runes (Ed.), (1972), Dictionary of philosophy (147-148). Totowa, NJ: Littlefield, Adams \& Company. Retrieved January 30, 2006, from http://suo.ieee.org/ontology/msg02534.html

Cohen, L., \& Manion, L. (1994). Research methods in education (4th ed.). London, New York: Routledge.

Council of Europe. (2008). White Paper on intercultural dialogue. Living together as equals in dignity. Strasbourg: Council of Europe.

European Commission. (2009). Early childhood education and care in Europe: Tackling social and cultural inequalities. Brussels: Education, Audiovisual and Culture Executive Agency (EACEA P Eurydice).

Frigg, S., \& Hartman, S. (2006, February 17). Models in science. In Stanford encyclopedia of philosophy. Retrieved October 26, 2009, from http://plato.stanford.edu/entries/ models-science/\#ModIndThe 
Gudjons, H. (2003). Pädagogisches Grundwissen (8. Auflage) [Basics of pedagogics (8th ed.)]. Bad Heilbrunn: Klinkhardt.

Hakkarainen, P. (2002). Kehittävä esiopetus ja oppiminen [A developing pre-school and learning]. Juva: WS Bookwell.

Helenius, A., \& Korhonen, R. (Eds.) (2008). Pedagogiikan palikat [Blocks of pedagogics]. Helsinki: WSOY.

Heylighen, F., \& Joslyn, C. (1992). What is systems theory? Retrieved January 15, 2009, from http://pespmc1.vub.ac.be/SYSTHEOR.html

Härkönen, U. (2003a). Mitä termit varhaiskasvatus ja esiopetus tarkoittavat? [What do the terms of early childhood education and preschool mean?]. Joensuu: University of Joensuu, Faculty of Education. Research Reports 86.

Härkönen, U. (2003b). The new systems theory of early childhood education and preschool as a frame for sustainable education. Journal of Teacher Education and Training, 2, 25-38. Daugavpils: Daugavpils University.

Härkönen, U. (2006). Diversity of early childhood education theories in a democratic society. Journal of Teacher Education and Training, 6, 103-115. Daugavpils: Daugavpils University.

Härkönen, U. (2008). New pedagogical systems theory and early childhood education culture. In U. Härkönen \& E. Savolainen (Eds.), International views on early childhood education. University of Joensuu, Savonlinna Department of Teacher Education. Retrieved June 15, 2009, from http://sokl.joensuu.fi/verkkojulkaisut/ varhais/harkonen.pdf ISBN 978-952-219-091-8 (pdf).

Härkönen, U. (2009). Vastauksena kysymykseen, mitä varhaiskasvatus on [As an answer for the question: What is early childhood education?]. Unpublished professorship inauguration lecture. Savonlinna: University of Joensuu, Savonlinna Department of Teacher Education.

Jämsä, T. (2006). The concept of sustainable education. A. Pipere (Ed.), Education \& Sustainable Development: First Steps toward Changes (Vol. 1, pp. 5-30). Daugavpils: Daugavpils University Publishing House "Saule".

Karvonen, E. (2003). Tiedotusopillinen ajattelu ja tutkimus [Thinking and research in communications theory and mass media]. Retrieved November 3, 2003, from http:/ /www.uta.fi/ tierka/S1syksy01eka/tsld029.htm

Lewins, A., \& Silver, C. (2007). Using software in qualitative research. London: SAGE Publications.

Palmquist, M. E., Carley, K. M., \& Dale, T. A. (1997). Two applications of automated text analysis. In C. Roberts (Ed.), Text analysis for the social sciences. Hillsdale, NJ: Lawrence Erlbaum Associates.

Parsons, T. (1968). Systems analysis: Social systems. In D. L. Sills (Ed.), International encyclopaedia of the social sciences, 15, 458-472. Macmillan Company \& the Free Press.

Rapoport, A. (1968). Systems analysis: General systems theory. In D. L. Sills (Ed.), International Encyclopedia of the Social Sciences, 15, 452-458. MacMillan Company \& The Free Press.

Robinson, M. (2008). Child development from birth to eight. McGrow-Hill Companies: Open University Press.

Schreiner, P. (2009). Research for education for sustainable development. In A. Skrinda (Ed.), The proceedings of the $7^{\text {th }}$ international JTEFS/BBCC conference "Sustainable 
development. Culture. Education.” (pp. 38-46). Daugavpils: Daugavpils University Academic Press "Saule".

Strauss, A.L. (1987). Qualitative analysis for social scientists. Cambridge: Cambridge University Press.

Senge, P. M. (2009) Systems thinking. Retrieved November 26, 2009, from http:// www.systemstnker.com/interests/systemsthinking/

Valsiner, J. (2000). Culture and human development. London: Sage.

Vasta, R. (Ed.). (2002). Kuusi teoriaa lapsen kehityksestä (2nd ed.) [Six theories of child development $\left(2^{\text {nd }}\right.$ ed. $\left.)\right]$. London: Jessica Kingsley.

Wikipedia. (2009, November 27). Systems thinking. Retrieved October 26, 2009, from http://en.wikipedia.org/wiki/Systems thinking

Wood, E. (Ed.). (2008). The routledger reader in early childhood education. London, New York: Routledge Taylor \& Francis Group.

\section{Correspondence:}

Ulla Härkönen, Professor in Education science, Savonlinna Department of Teacher Education, University of Joensuu, Box 86, 57101 Savonlinna, Finland. Email: Ulla.harkonen@joensuu.fi 